\title{
La conflictividad por servidumbres en los procesos judiciales de la Real Audiencia de Galicia en la Edad Moderna*
}

\section{Conflicts on easements in lawsuits at the Royal Court of Galicia in Early Modern History}

\author{
Rubén CASTRO REDONDO \\ Universidad de Santiago de Compostela \\ ruben.castro@usc.es
}

Fecha de recepción: 05-10-2017

Fecha de aceptación: 24-03-2018

\section{RESUMEN}

La sociedad gallega del Antiguo Régimen fue esencialmente conflictiva, hecho que ha sido probado en numerosas publicaciones en los últimos años. El presente artículo trata de analizar una parte de esta realidad social a través de los litigios que la Real Audiencia de Galicia atendió por razón de servidumbres, las cuales podían ser, según el elemento al que se refiriesen, de paso, de agua y de luces y ventanas. Estas figuras jurídicas redistribuían derechos y deberes al margen de la propiedad privada, por lo que aunque su fundamento no se discutía, como habitualmente ocurrió, sí se discutió la forma en que debían establecerse.

PALABRAS CLAVE: Edad Moderna, conflictividad social, servidumbre de paso, servidumbre de agua, servidumbre de luces y ventanas.

\section{ABSTRACT}

Galician society during Early Modern History was essentially conflictive, as many studies have demonstrated in recent years. This paper seeks to analyse a part of this social reality through the litigation that the Royal Court of Galicia considered by reason of easements, which could be, according to the element to which they refer, on rights of way, water, lights and windows. These legal instruments redistributed rights and duties beyond private property, so if their basis was not generally discussed, there was debate over how they should be established.

KEYWORDS: Early Modern History, social conflict, access easement, water easement, light and air easement.

\footnotetext{
* Este trabajo se ha realizado en el marco del Proyecto de Investigación Culturas urbanas: las ciudades interiores en el noroeste ibérico, dinámicas e impacto en el espacio rural, (HAR2015-64014-C3-3-R), financiado por el Ministerio de Economía y Competitividad de España y por la Unión Europea a través de los fondos FEDER.
} 


\section{INTRODUCCIÓN}

La convivencia en el seno de las comunidades vecinales de la Galicia moderna se vio alterada de manera constante por conflictos entre sus vecinos, aunque bien es cierto que pocas veces estos desencuentros alcanzaron niveles preocupantes de violencia. Una de las motivaciones habituales que rompían la paz social fueron las servidumbres, figuras jurídicas que restringían el concepto romano de propiedad —sobre la cual cabría uso y abuso-, imponiendo en cambio un nuevo reparto de derechos y obligaciones a cada uno de dichos vecinos.

Las servidumbres, reconocidas jurídicamente desde las recopilaciones de Alfonso $\mathrm{X}$, eran básicamente de paso y/o camino, de agua y de luces y ventanas. La primera obligaba a un propietario a permitir el paso de un extraño a través de su fundo, siempre que este demostrase que la propiedad a la que quería acceder no tenía salida a un camino público y, por ello, la única forma de llegar a ella era atravesando la(s) de los demás. En la segunda eran las aguas sobre las cuales recaía su fuerza jurídica, porque aun atravesando propiedades privadas, esas corrientes no podían alterarse si con ello se privaba de riego a las heredades por donde pasarían posteriormente. Y esto, en Galicia, el país de los mil ríos y con un minifundismo extremo, era motivo de constantes disputas. La tercera de las servidumbres tiene como sujeto jurídico las viviendas particulares, necesitadas de cierto control sobre su entorno más inmediato para disfrutar de iluminación en su interior o para evitar que cualquier elemento se interpusiese entre los edificios y el sol, principal fuente de luz y calor para los hogares del Antiguo Régimen.

\section{METODOLOGÍA}

El estudio de la conflictividad en las sociedades modernas presenta numerosas dificultades al investigador, derivadas todas ellas de la manifiesta imposibilidad de conocerla en toda su magnitud, toda vez que la ausencia de registro escrito para muchas de las disputas que se originaron en el seno de estas sociedades dominadas por la oralidad condenó al olvido a buena parte de ellas ${ }^{1}$. Pero, aunque su conocimiento completo será siempre inalcanzable, existen estrategias metodológicas que permiten acercarnos a ciertos tipos de conflictividad a través del estudio de las pruebas documentales que sí generó en su momento.

Nuestro estudio trata, precisamente, de acceder a la conflictividad que se produjo por razón de servidumbre(s) en la Galicia moderna mediante el análisis de la litigiosidad que estas disputas crearon. Por supuesto, el primer conjunto desborda al segundo, puesto que los conflictos son siempre mucho más numerosos que los litigios, si bien el estudio de estos es la principal vía - pero no la única ${ }^{2}$ - a través de la cual los investigadores podemos conocer los primeros. Es por eso que, a pesar de sus limitaciones, los procesos judiciales se convierten en el elemento clave para el estudio de la conflictividad que protagonizaron las sociedades de Antiguo Régimen³.

1 Estas son las denominadas "cifras negras" de la conflictividad en las sociedades del Antiguo Régimen, las cuales no fueron plasmadas en papel o bien porque la palabra bastaba o bien porque no todos tenían posibilidades de acudir ante las instituciones de justicia o ante los profesionales de la escritura: R. Iglesias Estepa, "La conflictividad 'sorda': un estudio sobre la criminalidad a finales del Antiguo Régimen", Obradoiro de Historia Moderna, 10 (2001), p. 257.

2 Otra de las alternativas metodológicas habituales suele servirse del estudio de los protocolos notariales, en particular de aquellas escrituras que contienen referencias a quebrantos de la paz social, desde apartamientos a concordias, las cuales recomponen la amistad entre dos individuos antes enfrentados sin necesidad de acudir a los tribunales.

3 T. A. Mantecón Movellán, Conflictividad y disciplinamiento social en la Cantabria rural del Antiguo Régimen, Santander, Universidad de Cantabria, 1997, p. 20: “(...) los procesos conservados no son todos los litigios que 
Para nuestro cometido se ha optado por estudiar los procesos judiciales relativos a servidumbre atendidos por la Real Audiencia de Galicia ${ }^{4}$. Este tribunal era el único con jurisdicción en todo el reino gallego, como resultado de dos competencias básicas que poseía en cuanto al conocimiento de procesos: en primera instancia, para cualquier pleito o causa incoada allí donde residiese el real tribunal y a cinco leguas alrededor; y en apelación, igualmente para todo litigio civil y criminal procedente de las justicias ordinarias ${ }^{5}$.

La restricción geográfica que puede presumirse de la primera competencia fue ampliamente superada por el hecho de que, desde 1480 hasta 1563, la Real Audiencia fue una institución itinerante, pero incluso tras su instalación permanente en la ciudad de A Coruña nunca perdió esta facultad, al servirse de sus alcaldes mayores para recorrer por turnos el territorio gallego. Estas vías de intervención —así como algunas otras ${ }^{6}$ — provocaron que la Audiencia se convirtiese de facto en un tribunal de justicia de primera instancia, tan accesible para la población como parecen indicar los más de 288.000 procesos que hoy conservamos en su archivo. Este soporte documental se convierte así en un excelente indicador de la litigiosidad que caracterizó a la sociedad gallega de Antiguo Régimen?.

Por el descomunal volumen de documentación que generó, pero también por su presencia en todo el territorio de la Galicia Moderna, su utilidad se impone al estudio de los litigios conservados en los archivos señoriales, en parte porque la mayoría de la documentación de estos no ha llegado a nuestros días, y en parte también porque aun conteniendo muchos más litigios, como así debió de ser, estos se habrían de referir exclusivamente a su espacio jurisdiccional.

Con todo, nuestra propuesta metodológica tiene sus limitaciones. La Real Audiencia, a pesar de su vasta presencia, no conoció todos los litigios acontecidos en la Galicia moderna, debido a que si un proceso no lo recibía en primera instancia, solamente lo podría conocer en apelación desde los tribunales ordinarios. Ahora bien, no todas las sentencias de los tribunales de primera instancia fueron recurridas, ni mucho menos. Xoán Miguel González Fernández demostró el escaso número de los recursos contra las sentencias emitidas desde la base del sistema judicial: por ejemplo, solamente un 9'60 \% de los procesos juzgados por el juez del Asistente de Santiago fueron apelados a la Real Audiencia; si se contrastan los datos con los que ofrece una justicia del ámbito rural, las cifras tampoco varían: en Bouzas sólo el 9'90 \% de los pleitos y el 7'80 \% de las causas fueron recurridas ante el tribunal coruñés ${ }^{8}$.

tuvieron lugar (...), aunque ofrecen una buena imagen del conjunto. No son la única fuente que permite una aproximación cuantitativa veraz sobre los problemas planteados, pero sí la única que añade a esta oportunidad el mayor aporte posible de información cualitativa sobre cada asunto sometido a la consideración judicial".

4 Conservados en el Archivo del Reino de Galicia (ARG).

5 Sobre las competencias del tribunal: L. Fernández Vega, La Real Audiencia de Galicia, órgano de gobierno en el Antiguo Régimen, A Coruña, Diputación de A Coruña, 1982, pp. 253-280; P. López Gómez, La Real Audiencia de Galicia y el Archivo del Reino, Santiago de Compostela, Xunta de Galicia, 1996, pp. 118-120; P. Ortego Gil, "La fuente limpia de la justicia: la Real Audiencia de Galicia", en Die Höchstgerichtsbarkeit im ZeitalterKarls V: Eine vergleichende Betrachtung, Baden Baden, Nomos, 2011, pp. 177-269.

6 La Real Audiencia actuaba en primera instancia en todos los "casos de corte" que tuvieran lugar en el territorio gallego, prioridad de intervención que ejecutaba igualmente mediante el "auto ordinario" o "auto gallego" y un total de XXXVII de sus "provisiones ordinarias": B. Herbella de Puga, Derecho práctico i estilos de la Real Audiencia de Galicia, Santiago de Compostela, Imprenta de Ignacio Aguayo, 1768, pp. 1-4 (casos de corte), pp. 16-45 (auto ordinario), pp. 185-241 (provisiones ordinarias).

7 O. Rey Castelao, Montes y política forestal en la Galicia del Antiguo Régimen, Santiago de Compostela, Universidad de Santiago de Compostela, 1995, pp. 16-21.

8 X. M. González Fernández, Bouzas y otros juzgados gallegos del siglo XVIII: la conflictividad judicial 
En realidad, tan solo el hecho de tener que acudir ante la Audiencia era motivo suficiente para pretender el fin de la disputa ${ }^{9}$, pues no es difícil intuir que el tiempo y las costas procesales derivadas de la actuación del máximo tribunal del reino desempeñarían un evidente carácter disuasorio, sobre todo para las disputas de menor valor, como es el caso.

El vaciado se ha llevado a cabo en las secciones de vecinos (5.285) y de particulares $(251.142)^{10}$, "el verdadero barómetro de la conflictividad social en Galicia ${ }^{11 ", ~ p o r q u e ~ e s ~}$ aquí donde de alguna manera se subsumen todas las demás secciones de los pleitos de la Audiencia. La sobrerrepresentación de expedientes particulares nos aportará, por una parte, una riquísima información de tipo cualitativo; pero, por otra parte, limitará nuestras opciones para dar respuesta a dicha actividad, toda vez que muchos de estos litigios se debieron más a inquinas personales que a problemas estructurales.

Salvando todas estas dificultades, la metodología empleada nos ha permitido cuantificar, ubicar y caracterizar una conflictividad de baja intensidad pero muy presente y persistente en la sociedad gallega tradicional.

\section{LOS LITIGIOS POR SERVIDUMBRES EN LA GALICIA MODERNA}

La litigiosidad que generaron las servidumbres en la Galicia del Antiguo Régimen y que se conserva entre los procesos de la Real Audiencia es abundante ${ }^{12}$. El conjunto de la muestra alcanza prácticamente 250 litigios, una cifra nada despreciable si nos atenemos a las consideraciones metodológicas previas (tabla 1).

Tabla 1. Los litigios por servidumbre en la Real Audiencia.

\begin{tabular}{|c|c|c|c|c|c|c|}
\hline Servidumbres & Individuales & $\%$ & Colectivos & $\%$ & Total & $\%$ \\
\hline Paso/camino & 150 & $93^{\prime} 75$ & 10 & 6.25 & 160 & $64^{\prime} 26$ \\
\hline Agua & 51 & $86^{\prime} 44$ & 8 & 13.56 & 59 & $23^{\prime} 69$ \\
\hline $\begin{array}{c}\text { Luces y } \\
\text { ventanas }\end{array}$ & 27 & $90^{\prime} 00$ & 3 & 10.00 & 30 & $12^{\prime} 05$ \\
\hline Total & 228 & $91^{\prime} 57$ & 21 & 8.43 & 249 & 100 '00 \\
\hline
\end{tabular}

Fuente: ARG, Real Audiencia.

ordinaria en la Galicia atlántica (1670-1820), Vigo, Instituto de Estudios Vigueses, 1997, pp. 207-217.

9 R. Kagan, Pleitos y pleiteantes en Castilla (1500-1700), Junta de Castilla y León: Consejería de Cultura y Turismo, 1991, p. 21.

10 Debido al tamaño de esta serie se ha trabajado con aquellos litigios que están catalogados e identificados con un pequeño regesto. Esta parte se corresponde con los demandantes cuyo apellido empieza por las letras A y B hasta "Bermúdez", los cuales suman 17.937 procesos.

11 O. Rey Castelao, Montes y política forestal..., p. 28.

12 A pesar de esto, esta conflictividad no fue estudiada de manera específica hasta el momento, aunque los fundamentos de estos derechos singulares habían sido ya descritos por Abel Bouhier en su obra ya clásica sobre la Galicia rural: A. Bouhier, La Galice: essai geographique d'analyse et d'interpretation d'un vieux complexe agraire, La Roche-sur-Yon, 1979. Sin duda, este investigador recogió aquí las influencias de las tesis doctorales que dos de los más grandes ruralistas franceses, Pierre Goubert y Jean Jacquart, habían defendido con anterioridad: P. Goubert, Beauvais et le Beauvaisis de 1600 á 1730 : contribution á l'histoire sociale de la France du XVIle siècle, París, l'École des Hautes Études, 1960; y J. Jacquart, La crise rurale en Île-de-France, 1550-1670, Paris, A. Colin, 1974. 
La distribución de los litigios es claramente irregular, tanto si nos referimos a su tipología como si lo hacemos a aquellos que la protagonizaron. En relación a la primera, dos tercios de los procesos se fundamentan en los problemas por servidumbres de paso y camino (64'26 \%), casi un cuarto por aguas (23'69 \%) y poco más de uno de cada diez lo hacen por luces y ventanas (12'05 \%); en relación a los protagonistas, en las tres categorías los sujetos individuales prevalecen sobre los colectivos, de manera que esta litigiosidad enfrentó en su mayoría a vecinos que actuaban de por sí (91'57 \%), lógicamente porque a fin de cuentas estos derechos se manifestaron la mayor parte de las veces sobre la propiedad de cada uno, ora la heredad, ora la vivienda.

\subsection{Los litigios por servidumbres de paso y camino}

Debido a la configuración de la propiedad de la tierra en la Galicia moderna — fragmentada hasta extremos sin parangón en heredades de pequeño tamaño-, muchas de sus parcelas de cultivo no tenían acceso desde un camino público, sino que sus propietarios estaban obligados a transitar eventualmente por las propiedades colindantes para acceder a la suya ${ }^{13}$. Por ello, las servidumbres de paso y camino y/o de entrada tuvieron una importancia capital para las sociedades campesinas del Antiguo Régimen ${ }^{14}$.

En realidad, las anteriores denominaciones tan solo especifican de qué modo un individuo de la comunidad va a ejercer dicho tránsito sobre la(s) propiedad(es) de su(s) vecino(s), si bien se debería hacer siempre a través del trayecto más corto posible entre el camino público y el predio dominante y/o la menor molestia ejercida sobre el predio sirviente.

Sea como fuese, las servidumbres no son más que derechos a través de los cuales se puede transitar legalmente por la propiedad de los demás con el único fin de alcanzar la de uno mismo ${ }^{15}$, lo cual consigue modificar de alguna manera los respectivos límites que separan una de otras; sin embargo, el fundamento y sobre todo la materialización de semejante derecho lo convierte en un fenómeno singular. Por una parte, el disfrute de un derecho más allá de las propias lindes se concreta de manera discontinua, esto es, solamente cuando aquel que disfruta de semejante derecho se dirige efectivamente hacia su propiedad —atravesando las del resto_- por lo cual su privilegio se prolonga tanto como el tiempo que le lleve recorrer dicho tránsito, y no más. Por otra parte, estas servidumbres crearon límites no tangibles sobre el territorio, pues no conllevaron la construcción de nuevos linderos que delimitasen el área de paso, entre otras cosas porque supondría romper la

13 Concepto y fundamento en: Las Siete Partidas del Rey don Alfonso el Sabio, cotejadas con varios códices antiguos por la Real Academia de la Historia, Madrid, 1807, P. 3, 31, 1: "que cosa es servidumbre: e quantas maneras son della", y P. 3, 31, 3: "qual es la llamada servidumbre rustica: e quantas maneras son della", respectivamente. Sobre su recepción en el Derecho común desde el sustrato romano: F. L. Pacheco, Las servidumbres pradiales en el derecho histórico español, Lleida, Pagès Editors, 1991; "Fueros y Partidas: algunas páginas más sobre servidumbres", Initium: Revista catalana d'historia del dret, 6, 2001, pp. 285-305. $14 \mathrm{Si}$ el tránsito desde el camino público era continuo, sin obstáculos, al propietario le bastaba con obtener servidumbre de paso sobre las heredades vecinas hasta su fundo, como la que Francisca Bermúdez de Castro demandó a su vecino Domingo de Castro en Elviña en 1679: Archivo del Reino de Galicia (ARG), Real Audiencia, leg. 9103, exp. 18. En cambio, si cualquiera de las heredades intermedias tenía alguna construcción que impedía acceder a ella, el derecho que se había de satisfacer de manera prioritaria era el de entrada, motivo por el cual se enfrentaron la viuda Inés Alonso do Río y el regidor de Mondoñedo, Luis de Luaces, en 1568: ARG, Real Audiencia, leg. 14753, exp. 21.

15 Motivo por el cual este fenómeno ha sido analizado en relación a la necesaria solidaridad que debe existir entre los vecinos-propietarios de una misma población: J. M. Cardesín, Tierra, trabajo y reproducción social en una aldea gallega (s. XVIII - XX): muerte de unos, vida de otros, Madrid, Ministerio de Agricultura, 1992, pp. 127 y ss. 
unidad de la propia heredad y porque aquellos solo tendrían utilidad en el breve tiempo que tomase el otro propietario en cruzar el fundo ajeno. A pesar de todo, el ancho que debía ocupar el paso sí tenía que delimitarse de alguna manera y para ello nada mejor que el recurso a la medición.

Desde la legislación alfonsina del siglo XIII quedó estipulado en pies la magnitud de aquel, y aunque el valor de esta medida estaba sujeto a variaciones zonales e interpretaciones de lo más interesadas, la demarcación por vía cuantitativa era siempre más precisa que cualquiera de las indicaciones cualitativas, como resultaba de las definiciones del tipo "el ancho suficiente" o el espacio que una persona ocupe al caminar a pie, o varias personas a la vez, pero "de manera que vayan uno ante otro e non empar ${ }^{16 "}$. Con todo, el legislador admitía que la limitación del ancho quedaba primero en manos de los involucrados, y solo en caso de no haber acuerdo se establecerían por defecto ocho pies para las vías, caso de que el perfil que atravesaban fuese derecho, y el doble si fuese sinuoso, para permitir la maniobra de los carros.

Si atendemos a la distribución cronológica de estos litigios, una primera lectura nos revela que la mayor concentración de aquellos se produce en la segunda mitad del siglo XVIII (gráfico 1). Aunque su análisis no sea sencillo por lo que se ha indicado en el apartado metodológico, sí hay ciertos elementos que parecen haber condicionado la intensidad y la cronología de los procesos por servidumbres de paso y camino.

Por lo pronto, parece plausible que la mayor concentración de procesos en momentos inmediatamente anteriores a 1600 que inmediatamente posteriores pudo deberse a la novedad judicial que significó el establecimiento de un tribunal real de apelación para todo el territorio gallego, de manera que lo que a menudo se buscaba era que este dictase una resolución firme en un conflicto/litigio que venía de viejo. Es cierto que los orígenes de la Real Audiencia se remontan a 1480, pero también es cierto que la conservación de litigios en el Archivo del Reino a duras penas antecede al año 1563, momento en el que se asienta definitivamente en la ciudad de A Coruña. Si esto es así, el uso de la justicia real durante el Quinientos tendría una finalidad más encaminada a probar por escrito un derecho apoyado en la costumbre que a demandarlo ex novo, con la única finalidad de 0 bien rematar definitivamente las viejas disputas o bien asegurarse la validez y la vigencia de dicho derecho ante posibles y futuribles conflictos ${ }^{17}$.

Al igual que ocurre en muchas otras categorías conflictivas relativas a la sociedad gallega de Antiguo Régimen, las primeras décadas del siglo XVII son las que presentan una menor cantidad de litigios. Entre 1600 y 1649 tan sólo se han podido datar 12 procesos por servidumbres de camino (7'50 \%), guarismo menor que los 18 que acopia tan sólo los 37 últimos años del siglo XVI (11'25 \%) y mucho menor que la cantidad de litigios que se producirán hasta el final del siglo XVIII: 27 entre 1650 y 1699 (16'88 \%), 29 entre 1700 y 1749 (18'13 \%) y 54 en la segunda mitad del siglo XVIII (33’76 \%).

16 Las Siete Partidas..., P. 3, 31, 3.

17 Un indicio de esto puede estar en la abundancia de "interdictos posesorios" en procesos del siglo XVI. Sobre esta figura se amparan tanto Esteban Álvarez en 1580 (ARG, Real Audiencia, exp. 17116, leg. 53), como Juan Alonso un año más tarde (ARG, Real Audiencia, exp. 20435, leg. 4). 
Gráfico 1. Cronología de los litigios por servidumbre de paso

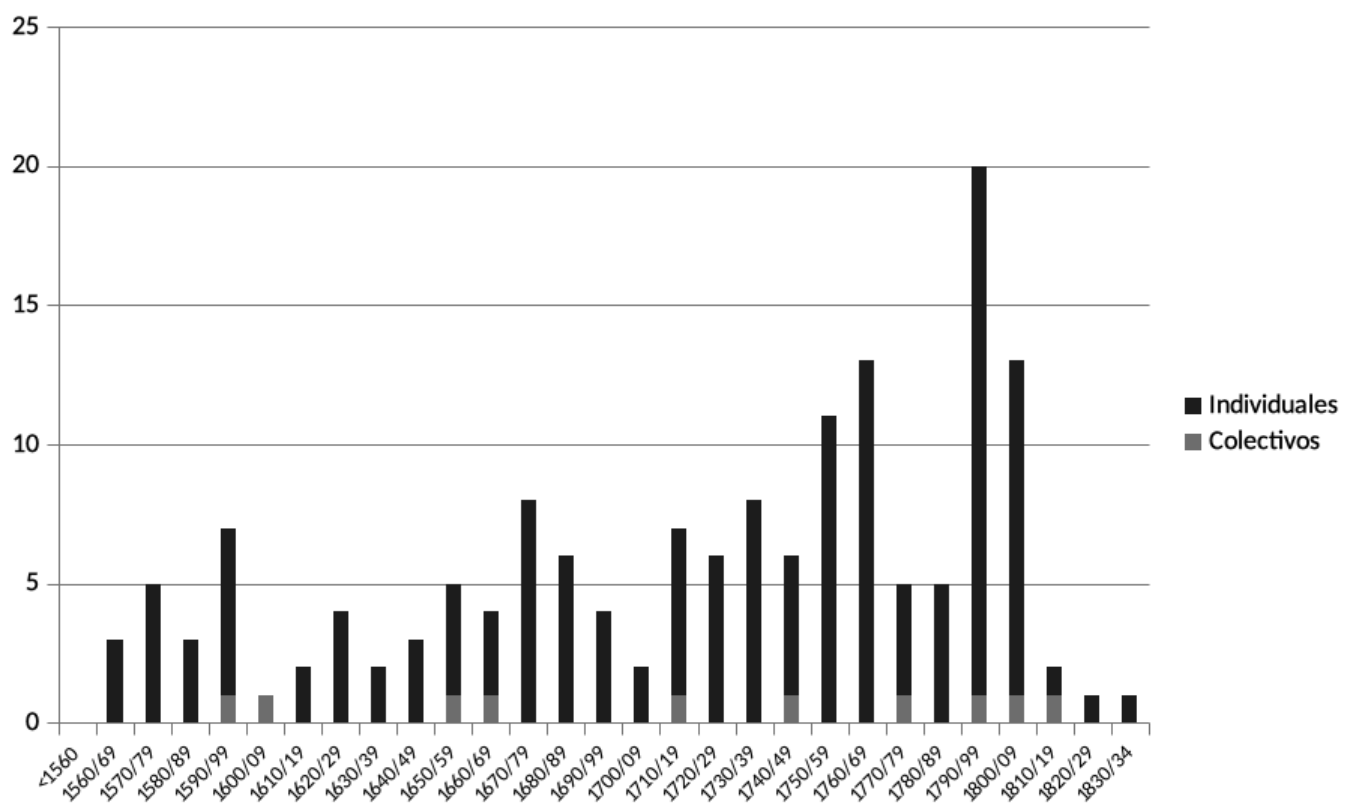

Fuente: ARG, Real Audiencia.

En relación a la condición social de los litigantes, ya sabemos que la sección de colectivos vecinales no aporta más que 6'25 \% de los procesos (tabla 1), resultado de la suma de las nueve ocasiones en que litigan contra un individuo y tan sólo otra ocasión más en que hacen lo propio contra otro colectivo vecinal ${ }^{18}$. En el caso de los pleitos entre particulares, los demandantes son mayoritariamente labradores y gentes del común (85'33 $\%$ ), seguidos de viudas (7'30\%), eclesiásticos (4\%), representantes de los oficios y cargos públicos (2'67 \%) y otra mujer (0’67\%), la cual —al contrario que las anteriores — se presenta como "mujer soltera" (tabla 2).

Tabla 2. Condición social de los demandantes/denunciantes por servidumbre de paso

\begin{tabular}{|c|c|c|}
\hline $\begin{array}{c}\text { Demandantes/ } \\
\text { Denunciantes }\end{array}$ & Número de litigios & $\%$ \\
\hline $\begin{array}{c}\text { Particulares del } \\
\text { común }\end{array}$ & 128 & $85^{\prime} 33$ \\
\hline Viudas & 11 & 7'33 \\
\hline Eclesiásticos & 6 & 4'00 \\
\hline $\begin{array}{c}\text { Cargos / Oficios } \\
\text { públicos }\end{array}$ & 4 & 2'67 \\
\hline Mujeres solteras & 1 & 100 '00 \\
\hline Total & 150 & \\
\hline
\end{tabular}

Fuente: ARG, Real Audiencia.

18 En 1595 los vecinos de Pontón y los de Barbadáns, ambos de la provincia de Ourense, pleitean por el derecho de paso entre unas viñas que se ubican específicamente en los límites de ambas poblaciones: ARG, Real Audiencia, exp. 22335, leg. 15. 
El perfil socioeconómico de los demandados por servidumbres de paso no difieren en demasía de los datos anteriormente señalados: la inmensa mayoría vuelven a ser gentes del común (79'33 \%), los cuales son acompañados a duras penas por representantes de oficios y cargos públicos (6’67\%) y eclesiásticos, viudas, licenciados y otros, todos los cuatro con porcentajes por debajo del $5 \%$ (tabla 3).

Tabla 3. Condición social de los demandados/denunciados por servidumbre de paso

\begin{tabular}{|c|c|c|}
\hline $\begin{array}{c}\text { Demandados/ } \\
\text { Denunciados }\end{array}$ & Número de litigios & $\%$ \\
\hline $\begin{array}{c}\text { Particulares del } \\
\text { común }\end{array}$ & 119 & 79 '33 \\
\hline $\begin{array}{c}\text { Oficios / Cargos } \\
\text { públicos }\end{array}$ & 10 & 6 '67 \\
\hline Eclesiásticos & 6 & 4 '00 \\
\hline Viudas & 6 & 4'00 \\
\hline $\begin{array}{c}\text { Licenciados y título } \\
\text { de "don" }\end{array}$ & 3 & $4^{\prime} 00$ \\
\hline Otros & 150 & 100 '00 \\
\hline Total & 6
\end{tabular}

Fuente: ARG, Real Audiencia.

Atendiendo a su procedencia, es evidente que el ámbito rural tiene que ser predominante en los conflictos de paso entre heredades en un territorio como el gallego (92'50 \% $)^{19}$, aunque no por ello las ciudades estarían excluidas; de hecho, hasta 12 de los litigios por derechos de paso se localizan en el interior de núcleos urbanos, lo que supone un 7'50 $\%$ del total (tabla 4$)^{20}$. En las villas y en las ciudades de la Edad Moderna tenían cabida también las propiedades orientadas al cultivo, de manera que los derechos de paso pueden ser necesarios para posibilitar el acceso a un predio de la misma manera que en el rural ${ }^{21}$. Pero, además, la concentración de viviendas en espacios reducidos podía privar a alguna de estas de un acceso directo a la calle y, en consecuencia, tener que solicitar paso, o bien

19 Xoán Miguel González Fernández había cuantificado 32 litigios por servidumbres de paso en un tribunal señorial rural como era el de Bouzas, lo cual equivale a un 4'48 \% del total de procesos atendidos por dicho tribunal entre 1740 y 1819. En el caso del Asistente compostelano, con jurisdicción sobre un territorio más urbanizado, las servidumbres de medianería, de luces y vistas y de "otras" suman tan solo 17 procesos durante todo el siglo XVIII, esto es, el 5'90 \% del total: X. M. González Fernández, Bouzas y otros juzgados..., pp. 96-101.

20 Hemos localizado tres en la ciudad de Ourense (ARG, Real Audiencia, exp. 14878, leg. 20; exp. 769, leg. 4; exp. 1346, leg. 20), dos en Vigo (ARG, Real Audiencia, exp. 12995, leg. 57; exp. 12261, leg. 29), y uno en Santiago (ARG, Real Audiencia, exp. 10125, leg. 30), A Coruña (ARG, Real Audiencia, exp. 9855, leg. 30), Lugo (ARG, Real Audiencia, exp. 19803, leg. 23), Pontevedra (ARG, Real Audiencia, exp. 21036, leg. 51), Monforte (ARG, Real Audiencia, exp. 8720, leg. 70), Ponteareas (ARG, Real Audiencia, exp. 2376, leg. 26) y Marín (ARG, Real Audiencia, exp. 11777, leg. 16).

21 En 1695 Bernardo Álvarez Becerra pleitea contra el teniente corregidor de A Coruña para obtener el derecho de paso a través de la heredad de este, llamada "de pie de Castelo": ARG, Real Audiencia, exp. 9855, leg. 30. 
a través de una heredad ${ }^{22}$, o bien a través de la casa de uno de los vecinos, derecho al que no muchos estaban prestos a acceder. Así ocurre en 1680 con Manuel Álvarez Enríquez, el cual se persona contra Antonio de Seoane para "no dar servidumbre por una casa que tiene en la ciudad de Orense ${ }^{23 \text { "; }}$ con esa misma reticencia y en esa misma ciudad, pero en 1727, Francisco Añel y Puga se niega a que Santiago Garrido transite por su casa de la calle del Tendal de Figueira como vía para acceder a la de él ${ }^{24}$.

Tabla 4. Procedencia de los litigios por servidumbre de paso

\begin{tabular}{|c|c|c|c|c|c|}
\hline Conflictividad & Total & Rural & $\%$ & Urbana & $\%$ \\
\hline $\begin{array}{c}\text { Servidumbres } \\
\text { de paso }\end{array}$ & 160 & 148 & $92^{\prime} 50$ & 12 & $7^{\prime} 50$ \\
\hline
\end{tabular}

Fuente: ARG, Real Audiencia.

De la forma en que se sustancian estos procesos sabemos que aquellos que acuden a la Real Audiencia para convertir en litigio un conflicto por servidumbre de paso lo hacían por cuatro grandes motivaciones, a saber: probar la costumbre en el derecho de servidumbre de una heredad, solicitar paso a través de un predio sirviente, denegar el paso hacia el predio dominante $\mathrm{y}$, finalmente, demandar cualquiera novedad que impidiese ejercer el derecho de paso sobre un determinado predio.

Con respecto a la primera, ya se ha indicado que su presencia será más intensa en esta conflictividad cuanto más reciente sea la fecha en que se sustancie el proceso, por la novedad judicial que inauguró la Real Audiencia. Si a la segunda motivación nos referimos, hay que tener en cuenta que en no pocos casos donde una heredad se había quedado enclavada entre más propiedades que la rodeaban completamente, la causa se ha de buscar en la división de una propiedad mayor y más antigua —esta sí con salida pública - de la cual derivaría aquella nueva porción encallada entre propiedades ajenas.

En este proceso el crecimiento demográfico tuvo que influir de alguna manera, pues el efecto que este provocaba era lógicamente un aumento del número de individuos entre los que se debía de fragmentar el patrimonio familiar a la muerte de los progenitores, por lo menos en una sociedad con un derecho hereditario que no excluía por defecto a ninguno de los hijos; sin embargo, la relación de esta conflictividad con la evolución de la población es difícil de visualizar, quizás porque sus efectos se produjeron al tiempo que la benigna situación económica que acompaña los ritmos demográficos los mitigaba, corrigiendo la mayor predisposición de comenzar un proceso judicial. En su defecto, hay algunos indicios de la presencia de esta causalidad, como es el hecho de que una de las partes que solicita derecho de paso lo haga a través de una propiedad de alguien con quien comparte apellidos ${ }^{25}$.

22 Ante esta tesitura se debió encontrar en 1689 Ignacio Andiano y Silva, vecino del barrio compostelano de Pitelos, pues demandó a Juan Álvarez Tejedor para ejercer sobre una heredad de este el derecho de paso hacia su propia vivienda: ARG, Real Audiencia, exp. 10125, leg. 30.

23 ARG, Real Audiencia, exp. 14878, leg. 20.

24 ARG, Real Audiencia, exp. 1346, leg. 20.

25 En 1730 Juan Ignacio Avalle demanda a Diego Jacinto Avalle, ambos de San Salvador de Coiro, a causa de una "servidumbre de camino por la veiga do prado": ARG, Real Audiencia, exp. 18763, leg. 13. 
En el caso contrario, un litigio podía también ser iniciado por el propietario del predio sirviente, esto es, por aquel que sufría las consecuencias de dejar transitar a extraños a través de su propiedad, como el que en 1612 enfrentó a Pedro Andrade de Soutomayor con sus vecinos del coto de Piñor, por "mantener cerrado y no dar camino por la heredad y término de Vigón"26".

Esta defensa del derecho negativo se hace más presente cuanta más molestia causaba el derecho de paso, pues este tránsito no tenía perfectamente delimitado sus límites y las vagas imprecisiones sobre estos daban lugar a continuos conflictos. El ancho del que se servía el que por una servidumbre se encaminaba a su heredad variaba en función de sus necesidades: el agravio que causaba el paso de una única persona —o de varias pero en fila de a $u^{27}$ - era menor que el que causaba el tránsito de una persona con dos bueyes ${ }^{28}$, y no digamos de esa misma persona al frente de dos carros de bueyes ${ }^{29}$. Pero la reacción ante estas servidumbres dependía también del valor que se le presuponía al área donde se establecían, de manera que es más frecuente que aflore cuando se trata de pasar por viñas ${ }^{30}$, huertas $^{31}$, bodegas ${ }^{32}$, granjas ${ }^{33}$, y sobre todo, por las propias viviendas ${ }^{34}$, al entenderse una intromisión intolerable allí donde se desarrolla el ámbito más íntimo del individuo.

Por último, otra de la motivación que conduce a dos partes a litigar en torno a una servidumbre de paso es la presencia de nuevos obstáculos que impedían el tránsito hacia el predio dominante. En la mayoría de estos casos el derecho de paso estaba probado desde antaño, pero este encontró en los cercamientos de heredades un claro competidor ${ }^{35}$. Sin embargo, este motivo está intrínsecamente ligado a otra de las categorías conflictivas por límites que hemos tipificado y su análisis va más allá del objetivo del presente artículo: nos estamos refiriendo a los litigios por aperturas y cierres de predios ${ }^{36}$.

\subsection{Los litigios por servidumbres de agua}

Si las servidumbres de paso obligaban a una propiedad a permitir su tránsito a otro que no fuese su dueño, siempre que fuese para conducirse hacia su heredad y solo cuando esta

26 ARG, Real Audiencia, exp. 3068, leg. 6.

27 En 1792 Francisco Abeiján y más de su parte se quejan a Inés de Vilachán sobre una "serventía de un camino de a pie": ARG, Real Audiencia, exp. 16667, leg. 53.

28 La servidumbre de paso de un carro con bueyes en Santo André de Lesta es el origen del litigio entre la viuda Cayetana de Castro y Barbeito y Antonio María de Castro, en 1802: ARG, Real Audiencia, exp. 11162, leg. 9. Más ejemplos: ARG, Real Audiencia, exp. 9967, leg. 13; ARG, Real Audiencia, exp. 10632, leg. 24.

29 En 1805 José Alonso Aguiar demanda a Francisco de Santiago "sobre el uso del tránsito para introducir dos carros": ARG, Real Audiencia, exp. 23828, leg. 1.

30 Algunos ejemplos de una larga lista: ARG, Real Audiencia, exp. 14723, leg. 17; ARG, Real Audiencia, exp. 1959, leg. 26; ARG, Real Audiencia, exp. 20683, leg. 54; ARG, Real Audiencia, exp. 5427, leg. 38; ARG, Real Audiencia, exp. 4437, leg. 49; ARG, Real Audiencia, exp. 23292, leg. 47; ARG, Real Audiencia, exp. 15776, leg. 10, etc.

31 ARG, Real Audiencia, exp. 9511, leg. 50.

32 ARG, Real Audiencia, exp. 23042, leg. 84; exp. 769, leg. 4; exp. 23358, leg. 59.

33 ARG, Real Audiencia, exp. 8720, leg. 10.

34 ARG, Real Audiencia, exp. 8329, leg. 20; exp. 1346, leg. 20; exp. 14878, leg. 20.

35 En 1618 Alonso Ares da Barreira demanda a Bernardo Maldonado por un muro que impide su derecho de paso a través de la heredad de este último: ARG, Real Audiencia, exp. 346, leg. 12. Por el mismo motivo Antonio Arias se queja de Ventura y de Bernardo Arias, todos ellos de Palas de Rei: ARG, Real Audiencia, exp. 19374, leg. 74.

36 R. Castro Redondo, La conflictividad vecinal en la Galicia de fines del Antiguo Régimen: Ios conflictos por medidas y límites (Tesis Doctoral Inédita), Universidad de Santiago de Compostela, 2016, pp. 434 y ss. 
no disfrutara de otro acceso público, las de agua forzaban a los predios sirvientes —aguas arriba- a permitir y respetar los cauces que los atravesaban para asegurar que su suministro llegase al (a los) predio(s) dominante(s) ${ }^{37}$ —aguas abajo- ${ }^{38}$.

También aquí la participación de colectivos vecinales es muy minoritaria (13’56 \%), pues los litigios incoados por particulares son claramente protagonistas (86'44\%). Si a los procesos en los que participan colectivos vecinales nos referimos, en todos y cada uno de ellos la demanda correspondiente va dirigida contra un particular — nunca contra otro colectivo-, siendo aquellos, siempre, gentes del común. En cambio, el análisis socioeconómico de los litigantes que participan en los 51 procesos iniciados por particulares nos muestra una composición más compleja, tanto en los demandantes como en los demandados.

Tabla 5. Condición social de los demandantes/denunciados por servidumbre de agua

\begin{tabular}{|c|c|c|}
\hline $\begin{array}{c}\text { Demandantes/ } \\
\text { Denunciantes }\end{array}$ & Número litigios & $\%$ \\
\hline $\begin{array}{c}\text { Particulares del } \\
\text { común }\end{array}$ & 43 & $84^{\prime} 31$ \\
\hline Eclesiásticos & 7 & $13^{\prime} 73$ \\
\hline Viudas & 1 & 1 '’96 \\
\hline Total & 51 & 100 '00 \\
\hline
\end{tabular}

Fuente: ARG, Real Audiencia.

Con respecto a los primeros (tabla 5), las gentes del común se encuentran detrás de la mayoría de las demandas por servidumbre de agua (84'31 \%), monopolio que tan sólo es discutido por la presencia de siete eclesiásticos (13'73 \%) y una única viuda (1'96 \%). En los segundos (tabla 6), los particulares llanos reciben casi ocho de cada diez demandas (78'43 $\%$ ), aunque el porcentaje restante se fragmenta en más categorías socioeconómicas que en el caso anterior, a saber: eclesiásticos (7'84 \%), licenciados y viudas (3'92 \% cada una) y oficios y cargos públicos, personas con título de don y otros (1'96 \%), todos los últimos tres con una presencia casi testimonial.

La serie de sus ritmos y de su intensidad difiere en parte de lo que se ha observado en la servidumbre precedente; sin embargo, antes de su presentación conviene puntualizar alguna que otra consideración metodológica de carácter específico. Los litigios por servidumbres de agua que hemos recogido no son más que aquellos que así se presentan en la sección de particulares y de vecinos en la Real Audiencia ${ }^{39}$, de manera que otros muchos que se habrán camuflado entre los procesos por los "usos y aprovechamientos de agua" o, incluso, los "usos y aprovechamiento de montes" — donde muchas veces nacían los cursos de agua ${ }^{40}$ — no encuentran acomodo ${ }^{41}$. Además, el carácter local y el pequeño

37 Las Siete Partidas..., P. 3, 31, 4: "como puede ome aver servidumbre en heredad agena para traer agua por ella".

38 E. Torijano Pérez, "El agua como bien privativo (de las Partidas al Código Civil)", en A. Marcos Martín (coord.), Agua y sociedad en la época moderna, Valladolid, Universidad de Valladolid, 2009, p. 83.

39 La sección de aguas en el ARG consta de nada menos que de 2.940 procesos.

40 O. Rey Castelao, Montes y política forestal..., p. 57.

41 Sobre la enorme litigiosidad que generó el uso y aprovechamiento de aguas en dicha Audiencia: X. M. Candal González, "Pleitos de aguas en la audiencia coruñesa durante el siglo XVIII", Obradoiro de Historia 
valor económico de estas servidumbres hacen que rara vez las demandas superen la instancia de las justicias señoriales, si es que llegan, porque son más que habituales las soluciones extrajudiciales que conservan las escrituras de los protocolos notariales ${ }^{42}$. Es por eso que, más que en otros casos, su presencia en los altos tribunales de justicia es puramente anecdótica ${ }^{43}$.

Tabla 6. Condición social de los demandados/denunciados por servidumbre de agua

\begin{tabular}{|c|c|c|}
\hline $\begin{array}{c}\text { Demandados/ } \\
\text { Denunciados }\end{array}$ & Número litigios & $\%$ \\
\hline $\begin{array}{c}\text { Particulares del } \\
\text { común }\end{array}$ & 40 & 78 '43 \\
\hline Eclesiásticos & 4 & 7'84 \\
\hline Licenciados & 2 & 3'92 \\
\hline Viudas & 2 & 3'92 \\
\hline $\begin{array}{c}\text { Cargos / Oficios } \\
\text { públicos }\end{array}$ & 1 & 1 '96 \\
\hline Título de "don" & 1 & 1 '96 \\
\hline Otros & 1 & $1 ' 96$ \\
\hline Total & 51 & 100 '00 \\
\hline
\end{tabular}

Fuente: ARG, Real Audiencia.

Con todo y con ello, el ritmo con que estas demandas llegan al tribunal herculino no es aleatorio, sino que responde básicamente a la distinta presión que las comunidades campesinas de la Galicia del Antiguo Régimen ejercieron sobre los recursos hídricos ${ }^{44}$. Entre las causas que explican la mayor o menor demanda de agua a lo largo de los siglos modernos destacan dos factores fundamentales: la extensión e importancia del praderío y la presencia -o no- de cultivos con necesidad de regadío, ejemplificados sobremanera en el maíz americano ${ }^{45}$.

Moderna, 2 (1993), pp. 85-103.

42 Así lo demuestran los estudios locales: Celia Alegre Maceira ponderó en un 4'60 \% los acuerdos que en la comarca del Ulla se firmaron ante notario sobre aguas, aunque esta problemática excede la categoría de nuestro interés, esto es, exclusivamente, las servidumbres de agua. En un dato similar, los poderes para iniciar un proceso - llegase o no a producirse - eran en el mismo ámbito espacial y cronológico de un 3'50 \%: C. Alegre Maceira, Dar e concordar no Ulla no século XVIII, A Coruña, Diputación provincial de A Coruña, 2009, pp. 64-68.

43 El análisis de los pleitos por aguas que realizó Xosé Manuel Candal reveló que casi un tercio de aquellos que llegaban a la Real Audiencia habían sido paralizados antes de conocer sentencia (31 \%): X. M. Candal González, "Pleitos por aguas...", p. 99 y ss. Sea como fuere, el tribunal herculino fue suficiente para atender las demandas que el uso y la posesión del agua produjeron en la Galicia del Antiguo Régimen: O. Rey Castelao, "La lucha por el agua en el país de la lluvia (Galicia, siglos XVI-XIX)", Vínculos de Historia, 1 (2012), p. 58.

44 J. M. Pérez García, "Entre regar y no regar: la intensa disputa por unos recursos hídricos colectivos escasos en la Galicia meridional (1600-1850)", en F. J. Aranda Pérez (coord.), El mundo rural en la España moderna, Cuenca, Universidad de Castilla la Mancha, 2004, pp. 555-572.

45 P. Saavedra Fernández, "El agua en el sistema agropecuario de Galicia", en A. Marcos Martín (coord.), 
Con todas las reservas, la serie de procesos nos indica tres aspectos clave. Uno, que si bien su presencia se documenta desde los primeros momentos en que la Real Audiencia se asentó en A Coruña, la intensidad de aquella es nimia hasta un siglo más tarde. Dos, que a partir de 1660 se evidencia una concentración de procesos que durará hasta final de siglo, con un máximo relativo en la década de 1680. Y tres, que tras 1730 se produce un aumento en el número de litigios por década, el cual se mantiene, mal que bien, hasta el final de la serie, siendo la segunda mitad del Setecientos el momento en que mayor concentración de pleitos por esta servidumbre se documentan: 25 entre 1750 y 1799, el 43'10 \%; y 29 entre 1740 y 1810 , el 49'15 \% (gráfico 2).

Gráfico 2. Cronología de los litigios por servidumbre de agua

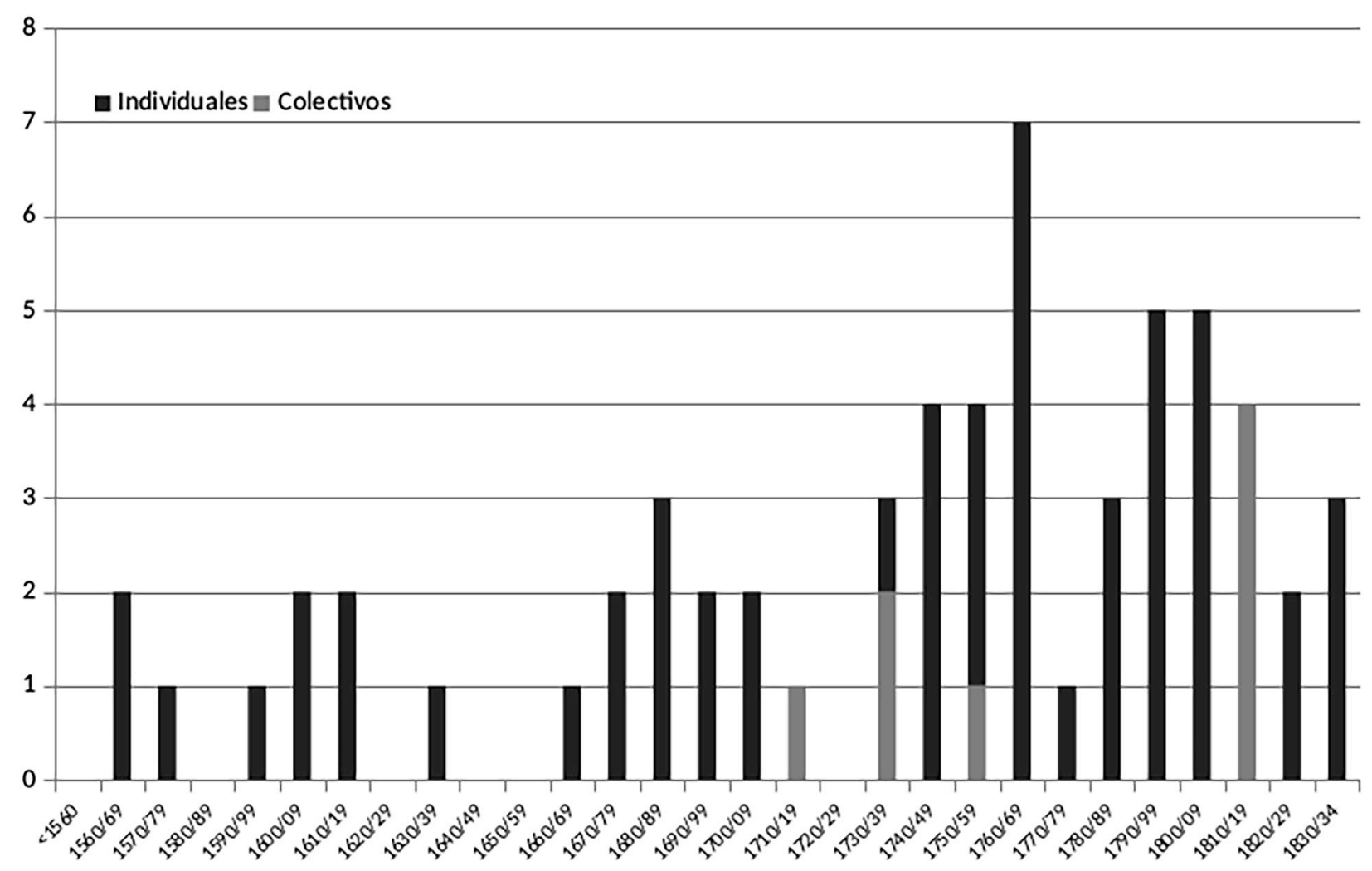

Fuente: ARG, Real Audiencia.

Si a todo lo anterior le adjuntamos su respectiva procedencia geográfica, las cosas se aclaran. De todos los procesos por servidumbres de agua que tienen lugar en el siglo XVII (12) -11 de ellos entre 1617 y 1697- al menos 8 de ellos, tienen su origen en las provincias atlánticas (66'67 \%)ㄴ. Tui (4), Santiago (3) y A Coruña (1), lo cual debe estar apuntando a una mayor demanda de agua en estos espacios a causa de la introducción del maíz, cereal necesitado de irrigación artificial ${ }^{47}$.

\section{Agua y sociedad..., pp. 49 y ss.}

46 Dos de los procesos no hemos podido ubicarlos geográficamente.

47 Los procesos más numerosos y más tempranos que se producen durante el siglo XVII tienen lugar en la zona donde antes y con mayor intensidad se innovó en dicho cultivo: la provincia de Tui (ARG, Real Audiencia, exp. 26603, leg. 42; exp. 3396, leg. 2; exp. 20890, leg. 35). Con el tiempo, los litigios aparecen también en dirección norte, allí donde se expande el cultivo: Caldas en 1635 (ARG, Real Audiencia, exp. 21267, leg. 20) o Dorrón en 1674 (ARG, Real Audiencia, exp. 21476, leg. 93). 
Tal y como se ha indicado en estudios precedentes ${ }^{48}$, los litigios por el uso de aguas aparecen más tardíamente en las provincias del interior, bien porque el maíz penetró aquí con retraso — cuando y donde efectivamente lo hizo - en comparación con la fachada occidental $^{49}$, o bien porque los otros condicionantes que propiciaron una mayor presión sobre los recursos hídricos en estas provincias no atlánticas se concentraron en el siglo XVIII. Estos son, fundamentalmente, la introducción del cultivo de la patata, el maíz del interior, la cual se extiende a partir de la segunda mitad del siglo XVIII5; y, sobre todo, las nuevas roturaciones de monte para dedicarlas al cultivo, las cuales se realizaron sin tregua desde finales del siglo XVII y que consiguieron de alguna manera alterar los riegos y los cauces de agua — muchas de ellas sometidas a servidumbres_, pues no vinieron sino a aumentar las necesidades de regadío en un sistema que, estacionalmente, era deficitario.

La construcción de molinos, por último, incrementó igualmente la competencia por el uso de agua que ya enfrentaba a cultivos y a ganados y, en muchas ocasiones, a cada uno de los anteriores por parte de diferentes poblaciones. En efecto, son los colectivos vecinales los que protagonizan la mayoría de los procesos donde la demanda se fundamenta en la privación de agua — de toda o de un caudal que se consideraba mínimo— por la "obra nueva" de un molino aguas arriba, los cuales emergen como la motivación más numerosa de los procesos por esta servidumbre a comienzos del siglo XIX. Así ocurre en 1811 entre los vecinos del concejo de Robledo de la Lastra y Rafael Morán, al que acusan "de haberles privado de agua al construir río arriba un molino en el terreno de Barranca ${ }^{51 " . ~ S i n ~ e m b a r g o, ~}$ los particulares también pleitearon contra la fábrica de nuevos molinos, habida cuenta que esta novedad podía privarlos del riego suficiente para mantener sus cosechas ${ }^{52}$.

En definitiva, las servidumbres de agua, allí donde se establecían, comprometían a cada propietario con la comunidad, pues tanto derecho tenía un vecino sobre esa "levada" fuera de su predio y aguas arriba como los demás sobre el mismo cauce cuando este se conducía por el interior de la propiedad de aquel. Es por esto que en las demandas por servidumbres de agua se pleitea sobre lugares, propiedades u obras ajenas, es decir, áreas sobre las cuales no se tiene derecho de propiedad alguno. Por ello, de alguna manera, las servidumbres de agua quebraron también los límites que configuraban las heredades agrarias, porque allí donde se establecieron aquellas, los derechos de propiedad ya no fueron prioritarios.

Una vez convenidas, heredadas o ganadas con el tiempo ${ }^{53}$, las servidumbres de agua eran garantía de la conservación del entorno en donde se ubicaba el fundo que las disfrutaba. Cualquier novedad que se producía entre este y el cauce que lo regaba, independientemente de la distancia relativa a la que se produjese, se convertía en un

48 P. Saavedra Fernández, "El agua en el sistema...", pp. 49-72; O. Rey Castelao, "La lucha por el agua...", pp. 45-79.

49 O. Rey Castelao, Montes y política forestal..., pp. 98 y 134.

50 P. Saavedra Fernández, "Servidumbres y limitaciones de dominio en el sistema agropecuario de Galicia", en Historia de la propiedad: servidumbres y limitaciones de dominio, Madrid, Servicio de Estudios del Colegio de Registradores, 2009, pp. 382-386.

51 ARG, Real Audiencia, exp. 12288, leg. 4. Cinco años más tarde son los vecinos de Rosal y Oimbra los que demandan a José Gallego por la construcción de un molino en el campo de "Insua e Porto Silveiro": ARG, Real Audiencia, exp. 21891, leg. 20; procedimiento que siguen los vecinos de Infesta (Monterrey) contra su vecino Miguel González: ARG, Real Audiencia, exp. 11304, leg. 1; y los de Redondela contra Florencio Rivas en 1818: ARG, Real Audiencia, exp. 12381, leg. 18.

52 ARG, Real Audiencia, exp. 1065, leg. 87.

53 Así se especifica desde las Siete Partidas de Alfonso X: Las Siete Partidas..., P. 3, 31, 14: "en quantas maneras puede ser puesta la servidumbre de las cosas". 
potencial motivo de disputa, por todo lo cual las roturaciones de monte, la implantación de nuevos cultivos, la parcelación de antiguos campos o pastos abiertos y la construcción de molinos se enfrentaron sistemáticamente a esta especial figura jurídica.

\subsection{Los litigios por servidumbres de luces y ventanas}

Al igual que las propiedades agrarias, las viviendas también podían gozar de servidumbres, por lo que los derechos de los que disfrutaba el propietario de un fundo e igualmente el área donde aquellos tenían vigencia quedaban limitados si en el polígono contiguo se había edificado una vivienda con derechos de servidumbre. Estos inmuebles en tanto que lugares de habitación tenían necesidades especiales, como la de recibir luz natural, y en virtud de estas gozaban de derechos específicos, como la de impedir cualquier obra que hecha a posteriori le privase de aquella. Sin embargo, las servidumbres de luces había que acordarlas entre los particulares en cuestión, pues el hecho de abrir una ventana en busca de luz sobre un predio ajeno significaba una intromisión que no todos estaban dispuestos a tolerar, al menos de buenas a primeras, lo que se tradujo en constantes conflictos, aunque muchos menos litigios.

La anterior aseveración se fundamenta en los pocos procesos que de la sección de vecinos y de particulares conserva la Real Audiencia con respecto a estas servidumbres urbanas (27). En realidad esta escasez es incluso lógica, porque por el lugar donde se materializaban estas servidumbres — la casa - se apartaba mayoritariamente a los colectivos de esta conflictividad — de hecho, no participan en ninguno-y el poco valor de las disputas disuadía a los individuos del común de largos y costosos procesos, los cuales llegaban con dificultades a la Real Audiencia y, en todo caso, allí fenecían.

Gráfico 3. Cronología de los litigios por servidumbre de luces y ventanas

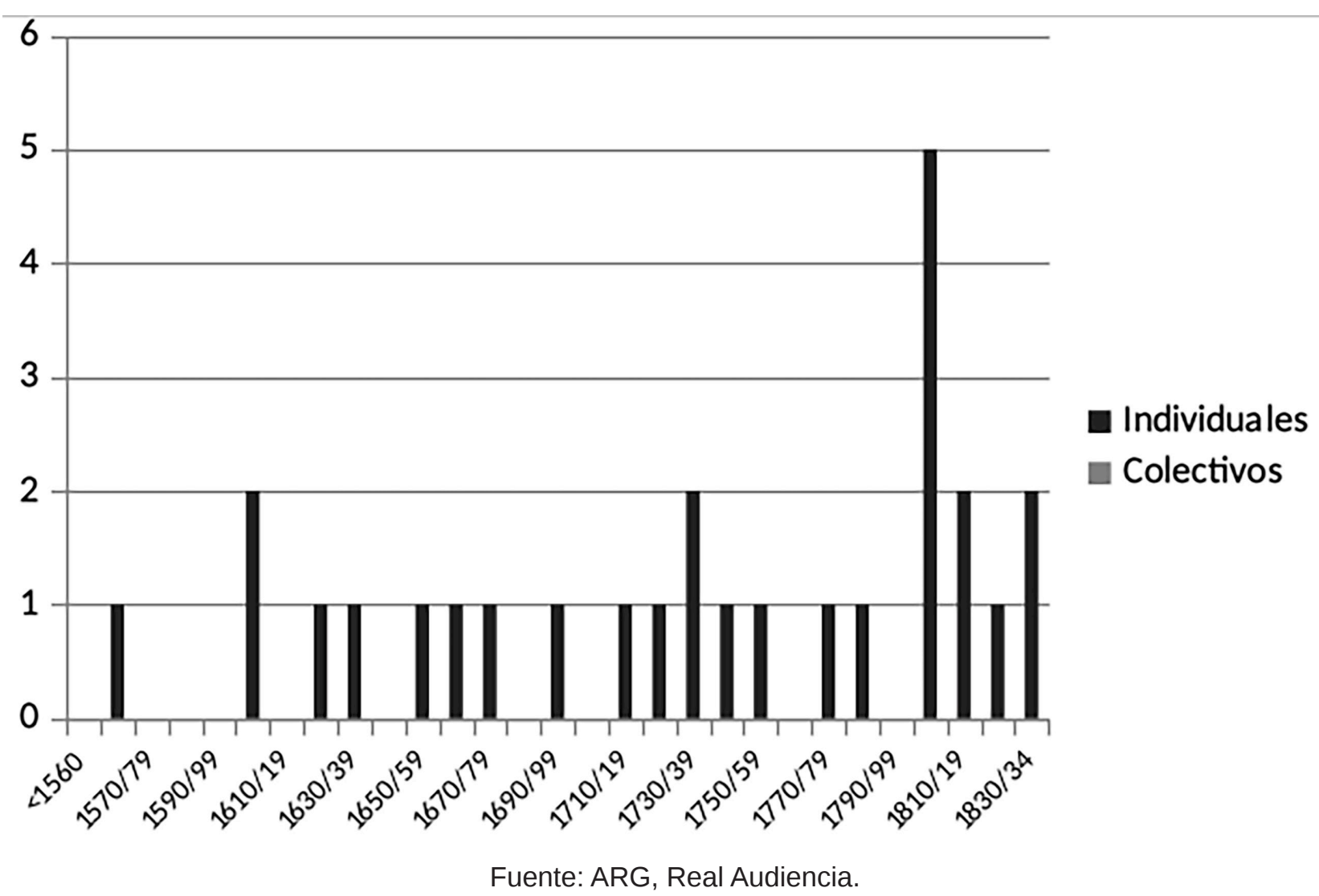


La intensidad de esta conflictividad tuvo que relacionarse de alguna manera con el crecimiento demográfico, y más específicamente, con el que experimentaron las áreas urbanas, pues es allí donde con mayor posibilidad se podría desencadenar un conflicto de esta naturaleza. En efecto, 17 de los 27 procesos (62'96 \%) se habrían originado en las ciudades (13) y en las villas (4), donde destacan aquellas que forman parte de las provincias atlánticas: A Coruña (3), Santiago (3), Tui (1), Ferrol (1) entre las primeras; o Corcubión (1) y Melide (1) entre las segundas. Así pues, los litigios se documentan en su mayoría en entidades con alta densidad de población y ubicadas en el área geográfica gallega demográficamente más dinámica, derivada dicha privilegiada condición de la favorable coyuntura agraria que proporcionó la introducción del maíz americano desde inicios del seiscientos.

Tabla 7. Condición social de los demandantes/denunciantes por servidumbres de luces y ventanas

\begin{tabular}{|c|c|c|}
\hline $\begin{array}{c}\text { Demandantes/ } \\
\text { Denunciantes }\end{array}$ & Número de litigios & $\%$ \\
\hline $\begin{array}{c}\text { Particulares del } \\
\text { común }\end{array}$ & 43 & $84^{\prime} 31$ \\
\hline Eclesiásticos & 7 & $13^{\prime} 73$ \\
\hline Viudas & 1 & 1 '’96 \\
\hline Total & 51 & 100 '00 \\
\hline
\end{tabular}

Fuente: ARG, Real Audiencia.

Toda vez que es el mundo urbano aquel que aglutina esta conflictividad, las instituciones que aquí se ubican estarán más expuestas a participar en ella. Como no podía ser de otra forma, una simple búsqueda de litigios por servidumbre de luces y ventanas en las series de Conventos (7), Nobleza (7), Colegios y Universidad (3), Monasterios (3), Cabildos e Iglesias (2), Cofradías (1) y Hospitales (1) de la Real Audiencia amplió nuestra casuística $(24)^{54}$, aunque los resultados no son comparables, pues en estos litigios las posibilidades económicas de unos y otros condicionaban que sus respectivas demandas llegasen - 0 no- a la audiencia herculina ${ }^{55}$. Sea como fuere, en nuestra muestra la mayor concentración de estos procesos se da ya iniciado el siglo XIX (gráfico 3).

El análisis sociológico de los litigantes muestra de nuevo un predominio de los particulares del común, tanto en su papel de demandantes (84'31\%) como de demandados (78'43 \%), seguidos a mucha distancia por eclesiásticos (13’73\%) y viudas (1'96 \%) en el primero de los casos (tabla 7), y de estos dos mismos sectores (7'84 \% y 3'92 \%, respectivamente) junto con licenciados (3'92\%), representantes de oficios y cargos públicos, personas con título de don y otros (1'96 \%) en el segundo (tabla 8).

54 ARG, Real Audiencia, exp. 1646, leg. 23; exp. 8306, leg. 52; exp. 2296, leg. 105; exp. 380, leg. 43; exp. 8117, leg. 7; exp. 1723, leg. 36; exp. 26501, leg. 24; exp. 26484, leg. 48; exp. 1296, leg. 24; exp. 1473, leg. 43; exp. 1743, leg. 43; exp. 1279, leg. 67; exp. 92, leg. 14; exp. 463, leg. 110; exp. 25037, leg. 69; exp. 330, leg. 3; exp. 1451, leg. 45; exp. 25647, leg. 45; exp. 1652, leg. 43; exp. 1652, leg. 44; exp. 1673, leg. 50; exp. 5115, leg. 40; exp. 26483, leg. 33; exp. 83, leg. 2.

$55 \mathrm{Si}$ el suelo urbano aglutinó buena parte de estas demandas, los archivos señoriales de las ciudades tienen que recoger más cantidad de litigios de los que aparecen en el ARG. Efectivamente, una simple búsqueda de estos en el Archivo de la Catedral de Santiago (ACS) nos muestra una intensidad mayor que la que se ha presentado. Algún ejemplo: ACS, pp. 067, 111, 135, 154, 162 у 210. 
Tabla 8. Condición social de los demandados/denunciados por servidumbre de luces y ventanas

\begin{tabular}{|c|c|c|}
\hline $\begin{array}{c}\text { Demandados/ } \\
\text { Denunciados }\end{array}$ & Número de litigios & $\%$ \\
\hline $\begin{array}{c}\text { Particulares del } \\
\text { común }\end{array}$ & 40 & 78 '43 \\
\hline Eclesiásticos & 4 & 7'84 \\
\hline Licenciados & 2 & 3'92 \\
\hline Viudas & 2 & 3'92 \\
\hline $\begin{array}{c}\text { Cargos / Oficios } \\
\text { públicos }\end{array}$ & 1 & 1 '96 \\
\hline Título de "don" & 1 & 1 '96 \\
\hline Otros & 1 & 100 '00 \\
\hline Total & 51 & \\
\hline
\end{tabular}

Fuente: ARG, Real Audiencia.

El motivo más habitual para iniciar un litigio por una servidumbre de luces se debía a la intromisión que alegaba el propietario contiguo a un inmueble cuando el titular de este "innovaba" en la apertura de una ventana: sin una servidumbre convenida, el primero protestaba por allanamiento y el segundo se defendía en la necesidad de recibir luz natural en su hogar. Si la ventana se abría sobre una propiedad que contenía otra vivienda, la intromisión era especialmente molesta por atentar contra la privacidad. En 1638, Pedro da Touza, vecino de la villa de Ribadavia, se quejó de su vecino Agustín Alonso porque "ningún derecho adquirido tienen (este y su hermano) para que pudiesen abir (sic) la dicha bentana, y ofenden notablemente a la cassa de mi parte porque le descubren todo el ynterior della ${ }^{56 "}$. No obstante, tampoco se toleraban aquellos otros orificios que se abrían sobre heredades no urbanizadas. En ambos casos, el propietario que se siente invadido solicita inmediatamente el cierre de esa ventana por vía judicial — se supone que tras agotar la vía del entendimiento verbal, aunque no necesariamente-, como de hecho pidió en 1777 Francisco Abad a Leonor da Silva, ambos residentes en la ciudad de Ferrol ${ }^{57}$.

En un proceso mucho más espectacular, Teresa Álvarez de Sotomayor apela a la ordinaria de viudas para tratar de evitar el auto del corregidor de Ourense en el cual se le mandaba el cierre inmediato de la ventana que había abierto sobre la heredad de Luis de Villamarín, motivo por el cual este último habría iniciado el litigio en 1562 ante la justicia de dicha ciudad, tal y como se recoge en su demanda:

(...) teniendo como mi parte tiene (...) unas casa sytas en la Fuente del Obispo que demarcan de una parte (...) con trasera de las casas de la dicha Taresa (...), e syendo como la dicha casa hes y sienpre fue libre de todas servidunbres hes ansí que podrá aver seys e siete anos (...) en la trasera de la dicha su casa y sobre la casa de mi parte de noche y surestiçia y clandestinamente abrió una bentana grande, e después de esto podrá aver un ano que en el

56 ARG, Real Audiencia, exp. 25846, leg. 41.

57 ARG, Real Audiencia, exp. 18982, leg. 51. Otros ejemplos: ARG, Real Audiencia, exp. 15846, leg. 41; exp. 26157, leg. 66. 
sobrado de arriba e sobre la casa (...) de mi parte abrió una puerta grande y hecho tres vigas junto a la puerta e sobre la dicha casa (...) no lo podiendo ni debiendo hazer por la casa de mi parte ser como hes e sienpre fue libre de toda servidumbre y la casa de la adbersa no tener semejante servidumbre sobre ella ${ }^{58}$.

Por supuesto, la parte de dicha viuda tratará de convencer a los jueces de que sus casas poseían dicho derecho sobre el lagar de su vecino y que, aún en el caso de que no se probase semejante servidumbre, las ventanas se habían abierto en un pasado muy remoto, y por no haber existido contradicción de dicho Luis hasta el momento, la demanda actual de este quedaba sin validez alguna ${ }^{59}$.

La solución judicial pasaba por hacer una "vista de ojos" para poder determinar la antigüedad de la ventana demandada, cosa que la Real Audiencia manda hacer al escribano real Rodrigo de Randín. Con ese propósito se dirigió este a las casas en conflicto junto con Nicolás de Yaspe y Bernaldo de Montesuras, pintores estantes en la ciudad de Ourense, "porque mejor pudiesen pintar la dicha diferençia y se pudiese mejor ver y entender por los dichos señores Gobernador e Oidores", de todo lo cual la imagen que adjuntamos a continuación es prueba de su buen hacer (figura 1) ${ }^{60}$.

Según la información contenida en el proceso también conocemos que otro de los fines que perseguía la viuda era el de que ni este ni ningún otro vecino "puedan alçar ni levantar la casa (...) ni su tejado más alto de lo que hasta ahora a estado, ni para ynpidir ni quitar la luz e claridad que las casas (...) an resçivido y por las dichas ventanas ${ }^{61 " .}$

Esta estrategia de construir una ventana sobre el predio de aquel vecino que quisiese alzar su vivienda con el único objetivo de paralizar sus intenciones fue más habitual de lo que pudiese parecer62. En 1733 y en la propia ciudad de Santiago, Blas de Antelo demandó ante la justicia ordinaria a don Fernando de Quiroga y a Manuel López Pacheco "sobre que zerrasen unas ventanas que corresponden sobre el texado de la casa del otorgante por el notable agravio que le hazen", de todo lo cual dicho Blas de Antelo había conseguido licencia por parte del Asistente de Santiago "para que pudiese suvir su casa ygual de las dos confinantes ${ }^{63 "}$. Los condenados apelaron a la Real Audiencia con la única excusa de haber sido demandados por "retocar una ventana de antiguo (...) con el pretesto de que era nueva fábrica", si bien el tribunal no lo entendió de la misma manera.

Si el daño que causaba la apertura de una ventana en la superficie de muros y paredes sobre el predio de un vecino era obvio y, con base en ello, la protección jurídica del propietario colindante era mayoritariamente aceptada, no parece que ocurriese lo mismo con las que se abrían en tejados y sobrados. Cuando en 1629 Pedro Alonso demanda a Alonso de Barros, ambos vecinos de Tui, "sobre el abrir una trapera en el texado" de la casa

$58 \quad$ ARG, Real Audiencia, exp. 14691, leg. 19.

59 En otro caso similar, originado en Ribadavia en 1814, Cayetano Martínez demandó a Felipe de Puente por suponer este último "que el referido tragaluz se hizo y fabricó aora de próximo pasado". Sin embargo, como señala la contraria, el muro sobre el que se presupone la obra nueva se fabricó "a cementis pasa de catorce años, y tiene en la referida pared un tragaluz que al mismo tiempo de dicha obra también hizo y edificó sin la menor contradición ni obposición, a vista ciencia y consentimiento de los sobredichos": ARG, Real Audiencia, exp. 25846, leg. 41.

60 ARG, Real Audiencia, exp. 167.

61 ARG, Real Audiencia, exp. 14691, leg. 19.

62 En uno de los procesos anteriormente citados, Pedro da Touza señala además que la ventana que de nuevo se había realizado sobre la heredad donde vivía "fue echa de malicia por pretender que mi parte no pueda levantar su cassa quando le paresca": ARG, Real Audiencia, exp. 25846, leg. 41.

63 ARG, Real Audiencia, exp. 23849, leg. 10. 
de este último y la justicia ordinaria le impera a cerrarla, el demandado apela dicho auto en razón de lo que a continuación reproducimos:

Dentro de las paredes de mi casa y sobre el texado della no se me pudo ympidir (hacer la ventana), que cada uno pueda açer en su açienda lo que quisere, aunque deso resulte algún dano particular, de otro quanto más no resultando ninguna en açer ventana en el texado de mi casa para claridad y adorno della, mayormente aviéndolas tenido muy más altas y vistas antes de aora ${ }^{64}$.

Figura 1. Vista de ojos en un pleito por apertura de ventanas

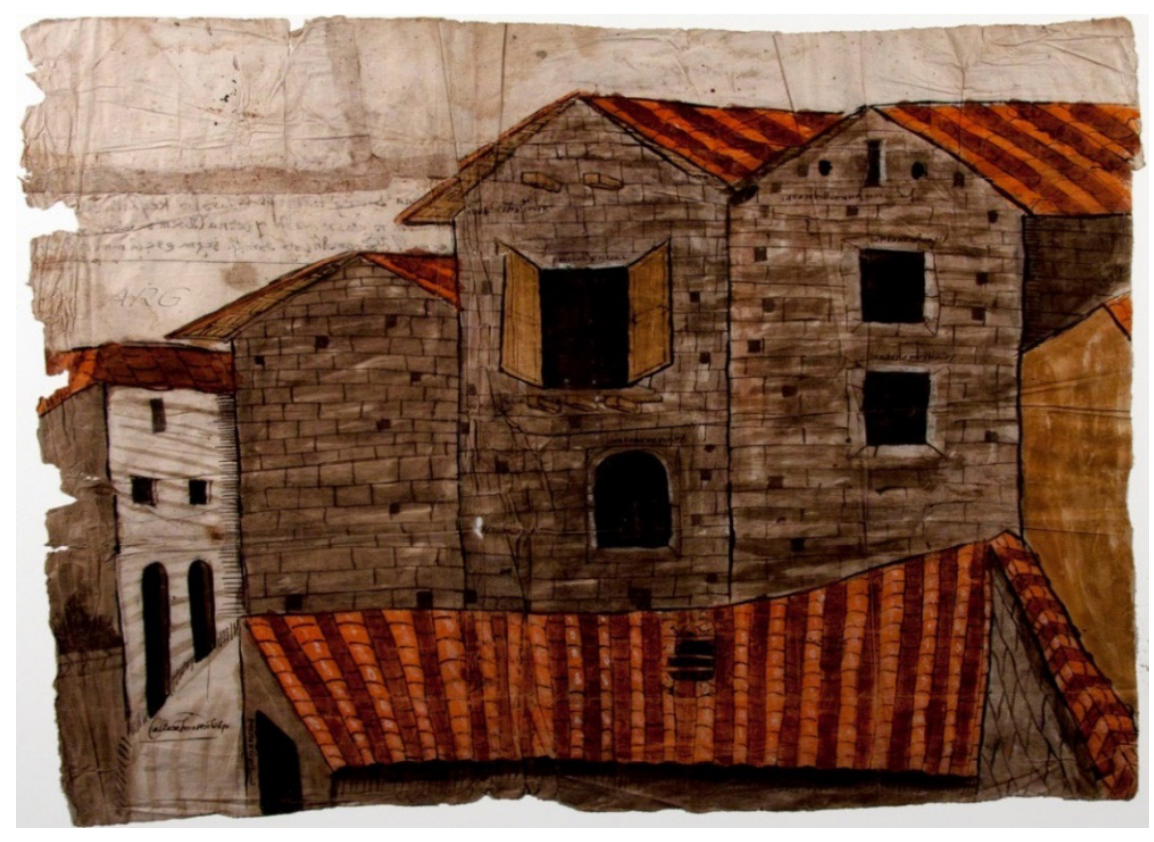

Fuente: ARG, Real Audiencia, exp. 167.

No ha de entenderse que la única posibilidad de que se originase un litigio de este tipo se debió a la apertura de uno de estos huecos hacia un predio sobre el que no se poseía servidumbre alguna, sino que también hay casos en los que una probada servidumbre de luces se ve perturbada por cualquier innovación que, realizada en el predio sirviente, obstaculizaba la luz entre la vivienda y el astro solar. En 1677 el escribano compostelano Francisco Bermúdez movió pleito contra su vecina Juana de Ulloa porque "theniendo una casa con dos altos en que bivía (...) y en el más alto della una bentana rasgada que le dava luz para el quarto della y que entrava el sol y rejistraba la calle", dicha Juana "por acerle molestia y agravio" subió su casa "pretendiendo ygualarla con la suia", de lo cual el primero sufrió notable perjuicio "por taparle la dicha ventana, quetándole la vista y servidumbre que siempre avía thenido y tenía sobre la casa de dicha Juana ${ }^{65 " . ~ D e ~ i g u a l ~ m a n e r a ~ y ~ e n ~ l a ~}$ misma urbe, el canónigo administrador del Hospital de San Roque denunciaba en 1801 al Conde de Gimonde por razón de "una casa a que se dio principio por la parte del norte e inmediata a la muralla de dicho Hospital con que se priva de sus luces ${ }^{66 " .}$

64 ARG, Real Audiencia, exp. 1845, leg. 27.

65 ARG, Real Audiencia, exp. 15899, leg. 24.

66 ARG, Real Audiencia, exp. 12339, leg. 38. 
Siendo esto así, los límites físicos entre de dos o más propiedades urbanas quedaban en papel mojado, pues la necesidad de luz natural en el interior de los hogares en un mundo todavía a oscuras urgía a sus inquilinos a buscar o mantener este suministro por todos los medios: si ya lo tenían asegurado, su cometido se limitaba a conservarlo, a costa de batallar con las "obras nuevas" que en su entorno se pudiesen construir; si no, las servidumbres de luces y ventanas podían servir, aunque conseguirlas no siempre era fácil. Sea como fuere, el crecimiento de la población en los entornos urbanos tuvo que estar detrás de muchas de estas disputas originadas a lo largo de la Edad Moderna, toda vez que esta novedad trajo consigo una creciente y constante construcción de viviendas o una ampliación de las ya existentes en forma de más alturas: en uno y otro caso, las obras sobre estos espacios no hicieron sino modificar su ordenamiento urbano y, en consecuencia, la posición relativa de cada uno de los hogares con respecto al astro rey.

\section{CONCLUSIONES}

La sociedad gallega del Antiguo Régimen fue esencialmente conflictiva y eso ha quedado reflejado en un uso constante y abundante de sus tribunales de justicia, lo cual a su vez la ha caracterizado como una sociedad extremadamente litigante.

Sea o no cierta esta querencia, algunas de las situaciones que prendieron la mecha del conflicto entre vecinos eran, si no inevitables, desde luego sí propicias. Con un régimen de propiedad atomizado hasta el absurdo, las posibilidades de que una heredad quedase completamente rodeada de otras y sin acceso público eran enormes, a la vista de los litigios que por esta causa se presentaron en la Real Audiencia de Galicia. Las servidumbres de paso vinieron a solventar en parte el problema existente entre este mosaico de propiedades y la creciente necesidad de acceso para muchas de sus teselas, de manera que esta solución que afectaba a cada propietario con sus homónimos colindantes, y así sucesivamente, sumó nuevos mimbres de solidaridad entre los miembros de cada comunidad.

Esta misma comunión se estableció sobre las aguas que atravesaban el espacio agrario, de tal forma que cada una de sus corrientes tuvo que ser respetada en su natural trayectoria, por mucho que a lo largo de esta se introdujese en fundos privados. Con todo, la presión a la que fueron sometidos los recursos hídricos por parte de una agricultura innovadora en cultivos y también por una población en aumento llevó a muchos individuos a luchar por uno de los numerosísimos cursos de agua que atravesaban el territorio gallego, los cuales eran estacionalmente insuficientes.

Las servidumbres no sólo afectaron al espacio agrario, sino que su utilidad se extendió también a las áreas donde los habitantes establecieron sus hogares. A medida que aumentaba la población lo hacía también la necesidad de nuevas viviendas, hecho que vino acompañado de un crecimiento paulatino pero firme de las ciudades en el noroeste peninsular. Ambos factores trajeron consigo una mayor densidad de casas en las entidades de población y con ella una redistribución del espacio urbano. Como obras necesitadas de luz exterior, muchos de sus moradores compitieron con sus vecinos para ganar o garantizar orificios que iluminasen y calentasen cada día su hogar. Esta especial necesidad ocasionó conflictos novedosos para esta sociedad cada vez más urbanizada, pues las ventanas que se abrían al exterior dejaban pasar la luz pero también la mirada de curiosos y extraños, al tiempo que permitían a esos mismos inquilinos asomarse sobre las propiedades contiguas.

Todas estas servidumbres fueron configurando una forma particular de vecindad en la Galicia moderna, no carente de conflictos, por supuesto, pero donde el derecho de propiedad no fue el único que ordenó la interacción entre sus individuos, como a menudo se ha insinuado. Antes bien, las necesidades especiales de este espacio que agros y habitantes configuraron obligaron a una solidaridad comunitaria a las que pocas veces se alude. 


\section{Siglas de los archivos consultados}

Archivo de la Catedral de Santiago (ACS)

Archivo del Reino de Galicia (ARG)

\section{BIBLIOGRAFÍA}

Alegre Maceira, C., Dar e concordar no Ulla no século XVIII, A Coruña, Diputación provincial de A Coruña, 2009.

Bouhier, A., La Galice: essai geographique d'analyse et d'interpretation d'un vieux complexe agraire, La Roche-sur-Yon, 1979.

Candal González, X. M., "Pleitos de aguas en la audiencia coruñesa durante el siglo XVIII", Obradoiro de Historia Moderna, 2 (1993), pp. 85-103.

Cardesín, J. M., Tierra, trabajo y reproducción social en una aldea gallega (s. XVIII - XX): muerte de unos, vida de otros, Madrid, Ministerio de Agricultura, 1992.

Castro Redondo, R., La conflictividad vecinal en la Galicia de fines del Antiguo Régimen: los conflictos por medidas y límites (Tesis Doctoral Inédita), Universidad de Santiago de Compostela, 2016.

Fernández Vega, L., La Real Audiencia de Galicia, órgano de gobierno en el Antiguo Régimen, A Coruña, Diputación de A Coruña, 1982.

González Fernández, X. M., Bouzas y otros juzgados gallegos del siglo XVIII: la conflictividad judicial ordinaria en la Galicia atlántica (1670-1820), Vigo, Instituto de Estudios Vigueses, 1997.

Goubert, P., Beauvais et le Beauvaisis de 1600 á 1730 : contribution á l'histoire sociale de la France du XVIle siècle, París, l'École des Hautes Études, 1960.

Herbella de Puga, B., Derecho práctico i estilos de la Real Audiencia de Galicia, Santiago de Compostela, Imprenta de Ignacio Aguayo, 1768.

Iglesias Estepa, R., "La conflictividad 'sorda': un estudio sobre la criminalidad a finales del Antiguo Régimen", Obradoiro de Historia Moderna, 10 (2001), p. 247-273.

Jacquart, J., La crise rurale en Île-de-France, 1550-1670, Paris, A. Colin, 1974.

Kagan, R., Pleitos y pleiteantes en Castilla (1500-1700), Junta de Castilla y León: Consejería de Cultura y Turismo, 1991.

Las Siete Partidas del Rey don Alfonso el Sabio, cotejadas con varios códices antiguos por la Real Academia de la Historia, Madrid, 1807.

López Gómez, P., La Real Audiencia de Galicia y el Archivo del Reino, Santiago de Compostela, Xunta de Galicia, 1996.

Mantecón Movellán, T. A., Conflictividad y disciplinamiento social en la Cantabria rural del Antiguo Régimen, Santander, Universidad de Cantabria, 1997.

Ortego Gil, P., "La fuente limpia de la justicia: la Real Audiencia de Galicia", en Die Höchstgerichtsbarkeit im ZeitalterKarls V: Eine vergleichende Betrachtung, Baden Baden, Nomos, 2011, pp. 177-264.

Pacheco, F. L., Las servidumbres pradiales en el derecho histórico español, Lleida, Pagès Editors, 1991.

Pacheco, F. L., "Fueros y Partidas: algunas páginas más sobre servidumbres", Initium: Revista catalana d'historia del dret, 6, 2001, pp. 285-305.

Pérez García, J. M., "Entre regar y no regar: la intensa disputa por unos recursos hídricos colectivos escasos en la Galicia meridional (1600-1850)", en F. J. Aranda Pérez (coord.), El mundo rural en la España moderna, Cuenca, Universidad de Castilla la Mancha, 2004, pp. 555-572.

Rey Castelao, O., Montes y política forestal en la Galicia del Antiguo Régimen, Santiago de Compostela, Universidad de Santiago de Compostela, 1995. 
Rey Castelao, O., "La lucha por el agua en el país de la lluvia (Galicia, siglos XVI-XIX)", Vínculos de Historia, 1 (2012), pp. 45-72.

Saavedra Fernández, P., "El agua en el sistema agropecuario de Galicia", en A. Marcos Martín (coord.), Agua y sociedad en la época moderna, Valladolid, Universidad de Valladolid, Instituto Universitario Simancas, 2009, pp. 49-72.

Saavedra Fernández, P., "Servidumbres y limitaciones de dominio en el sistema agropecuario de Galicia", en Historia de la propiedad: servidumbres y limitaciones de dominio, Madrid, Servicio de Estudios del Colegio de Registradores, 2009, pp. 351-388.

Torijano Pérez, E., "El agua como bien privativo (de las Partidas al Código Civil)", en A. Marcos Martín (coord.), Agua y sociedad en la época moderna, Valladolid, Universidad de Valladolid, 2009, pp. 73-86. 